Article

\title{
Area-Based Urban Renewal Approach for Smart Cities Development in India: Challenges of Inclusion and Sustainability
}

\author{
Sarbeswar Praharaj \\ Knowledge Exchange for Resilience, School of Geographical Sciences and Urban Planning, Arizona State University, USA; \\ E-Mail: s.praharaj@asu.edu
}

Submitted: 7 May 2021 | Accepted: 1 July 2021 | Published: 17 November 2021

\begin{abstract}
Cities in the Global South face rapid urbanization challenges and often suffer an acute lack of infrastructure and governance capacities. Smart Cities Mission, in India, launched in 2015, aims to offer a novel approach for urban renewal of 100 cities following an area-based development approach, where the use of ICT and digital technologies is particularly emphasized. This article presents a critical review of the design and implementation framework of this new urban renewal program across selected case-study cities. The article examines the claims of the so-called "smart cities" against actual urban transformation on-ground and evaluates how "inclusive" and "sustainable" these developments are. We quantify the scale and coverage of the smart city urban renewal projects in the cities to highlight who the program includes and excludes. The article also presents a statistical analysis of the sectoral focus and budgetary allocations of the projects under the Smart Cities Mission to find an inherent bias in these smart city initiatives in terms of which types of development they promote and the ones it ignores. The findings indicate that a predominant emphasis on digital urban renewal of selected precincts and enclaves, branded as "smart cities," leads to deepening social polarization and gentrification. The article offers crucial urban planning lessons for designing ICT-driven urban renewal projects, while addressing critical questions around inclusion and sustainability in smart city ventures.
\end{abstract}

\section{Keywords}

ICT; inclusion; India; smart cities; Smart Cities Mission; sustainability; urban renewal

\section{Issue}

This article is part of the issue "Towards Digital Urban Regeneration: Embedding Digital Technologies Into Urban Renewal Processes and Development" edited by Dalit Shach-Pinsly (Technion-Israel Institute of Technology, Israel).

(C) 2021 by the author; licensee Cogitatio (Lisbon, Portugal). This article is licensed under a Creative Commons Attribution 4.0 International License (CC BY).

\section{Introduction}

Debates about the future of urban development and planning have been increasingly driven by discussions of smart cities (Batty et al., 2012; Hollands, 2008; Kitchin, 2014; Townsend, 2013; Yigitcanlar, 2015), with many smart city projects surfacing worldwide. Open data, the internet of things, and new digital urban solutionfocused public-private partnerships are critical pillars of the smart city strategies in the European cities of Barcelona, Amsterdam, Dublin, and London (Caragliu et al., 2011). In Australia, a $\$ 50$ million "smart cities and suburbs program" (Dowling et al., 2019; Rahmat et al., 2020) materializes Sydney's smart mobility project and
Melbourne's Interactive City Management Platform-a sensor network for collecting data on the use of public spaces. In the USA, several cities have opened avenues to renovate urban spaces into technological testbeds resulting in transformative projects such as the LinkNYC in New York, a first-of-its-kind communications network providing fast and free public $\mathrm{Wi}-\mathrm{Fi}$, phone calls, device charging, and interactive tablet-screen for accessing city services, maps, and directions (Shapiro, 2018; Sinky et al., 2018). The technology-driven urban development policy has made deep inroads in Asia, too, with more than 500 smart cities coming up across China (Bacchi, 2020) and 100 cities selected for development under the Smart Cities Mission (SCM) in India (Praharaj et al., 2018b). 
Recent studies suggest smart cities will grow in popularity and value in the post-pandemic world (Kunzmann, 2020), with the global market for urban technologyintensive services soaring up to $\$ 3$ trillion by 2027 .

While ICT and digital solutions have indeed uplifted quality of life and improved service delivery models in many cities across the world, researchers argue that the impacts of smart city interventions are not always equitable (Nugent \& Suhail, 2021; Seta et al., 2015). The first concern surrounds the question: Who is the target audience of high-tech urban investments? Hollands (2008) found that smart cities often have a narrow spatial focus to create infrastructure for a specific (in most cases affluent) area of the city, designed to attract high visibility. The assumption is that the potential mushrooming of smart pilot projects will somehow assimilate into a utopian smart city (Townsend, 2013). However, researchers rarely investigate the social impacts of these so-called smart projects, leaving critical questions unanswered. Beretta (2018), while examining smart cities in Italy, argues that smart cities' benefits do not extend to all citizens; instead, they are designed for the better halves, risking-among other things-promotion of the phenomenon of gentrification. Wiig (2015) suggests smart cities demonstrate a new form of corporate-driven development where international firms are engaged in transporting urban technology solutions from one part of the world to the other, which McCann (2011) calls urban policy mobilities and global circuits of knowledge. Such approaches promote a one-size-fits-all model of urbanism (Han \& Hawken, 2018) that is a significant barrier to shaping a culturally sensitive and inclusive urban landscape.

Moreover, the smart cities commentary suffers from a "north-centrism" (Robinson, 2003) ailment, with most critical urban technological studies focusing overwhelmingly on the parameters, processes, and practices in the Global North (Praharaj et al., 2018a, 2018b). Söderström et al. (2014) suggest the smart city promoters take for granted that foundational infrastructures are already in place in the cities for technology to improve their efficiency. They fail to consider the context of most cities in the Global South, where lack of services, spatial inequality, and unmanaged infrastructure systems is the norm. Considering the increasing rate of smart city efforts in the Global South and an estimated $81 \%$ of the five billion population expected to live in the region by 2030 (United Nations, 2019), the need for on-ground investigations of case studies to address the existing knowledge gaps is evident to shape inclusive, sustainable, and resilient cities.

This study critically investigates the smart cities development in India to highlight the inconsistencies between the promise and delivery of the technologydriven urban development model. The article seeks to answer the research question of whether the digital urban renewal strategies put forward by the Indian cities provide a practical approach for shaping sustainable and inclusive cities or not. This research views "sustainabil- ity" and "inclusion" as intertwined concepts that help us examine how urban systems function, remain diverse, and produce solutions for communities to sustain our modern way of life. The two concepts help us assess what processes were adopted to identify projects and solutions, which communities are served or excluded by the smart city ventures, how their implementation impacts the social and economic fabric, and whether the overall outcome leads to sustainability and inclusion. The approach to study "sustainability" in this article explores the fine line between competing needs of digital urban transformation and the need to protect the social and community networks in which our populations lives. We follow James (2014) in emphasizing that "sustainability" is not just about the environment or economy; it is also about our health as a society in ensuring that people are not excluded or suffer because of new policies of grand urban (re)developments.

This study is both timely and essential as India implements one of the world's most extensive smart city program engaging 100 cities and a \$14 billion investment. Indian authorities adopt an area-based development (ABD) approach (Praharaj et al., 2018c) with intensive use of ICT to develop certain parts of the city as "smart precincts," more critically referred to as "smart enclaves" (Hollands, 2008). These ABDs cover a meagre average of $2.4 \%$ of the total area per city-however, a staggering $81 \%$ of the total funds are being allocated to develop these exclusive zones (Housing and Land Rights Network, 2018). The skewed investment towards creating exclusive enclaves threatens to magnify an alreadyexisting intra-city divide and social segregation unique to developing world cities (Mitlin \& Satterthwaite, 2013; Seta et al., 2015). The current study is critical as these developments pose irreversible consequences for innercity gentrification, ignoring social sustainability in shaping urban landscapes, as smart cities have to be inclusive, not just technological (Nam \& Pardo, 2011; Yigitcanlar et al., 2019). Coe et al. (2001, p. 90) fittingly argue that "local community partnerships-not wires-are the fibers that bind" smart communities and cities. The findings from this study advance knowledge and build on the critical smart city studies while offering a broad and large-scale perspective on integrating digital technologies into urban renewal decisions moving towards smart city development.

\section{Review of the Global Discourse on Smart Cities and Their Interplay With Digital Urban Renewal}

In the fields of urban planning and public policy, researchers use "smartness" as a normative claim that essentially means efficient urban management. Being smarter indicates a specific strategic policy direction adopted by urban authorities to distinguish their new policies and development programs (Yigitcanlar, 2015). The smart city concept has become topical in academic and policy discussions in recent times. However, the 
phrase "smart city" is not new. Downs (2005) suggests that the concept originated in the late 1990s as part of the USA's "smart growth movement." The phrase became widely recognized after it was adopted by several global technology corporations, including IBM, which defines the smart city as an "instrumented, interconnected and intelligent city that uses ICT to sense, analyze and integrate critical information on core systems in running cities" (IBM, 2008, p. 2). The focus of the smart city discourse largely rests on the role of ICT in efficiently managing urban infrastructure and services. Over the last decades, the concept has evolved to mean almost any form of technology-driven innovation in urban management and operations with wide-ranging applications in areas of mobility, environmental management, emergency command and control center (Praharaj, 2020), and energy efficiency.

Alongside technology, a fundamental characteristic of smart cities is their underlying emphasis on selfbranding and image building to attract businesses and the creative class (Florida, 2005). Smart cities are an emerging information marketplace with a strong reliance on ICT networks and market networks (Cosgrave et al., 2013). To this end, experts apply system thinking to scope how concepts of the "living lab" and the "innovation districts" work together in a complementary fashion to create a candidate model for implementing the smart city. The premise of the living lab is that the city can be used as a real-world testing ground for new technologies, sensors, and wireless networks that enhance innovation and the creation of new products and urban solutions (Baccarne et al., 2014). Experimentation with technology is also a core philosophy of innovation districts which are small, gentrified pockets in a city supposed to bring together start-up companies and creative industries clustered in large, skilled, economically diverse, and wellconnected urban environments. The "triple helix theory" builds on these foundations of living lab and innovation districts (Pancholi et al., 2019) where creativity supposedly stimulates new links, fluid exchange of ideas, technologies, and information between the industry, government, and universities, creating a backbone for smart city collaboration (Yigitcanlar et al., 2020).

From Google's Sidewalk Labs engagement in Toronto waterfront renewal (Morgan \& Webb, 2020) to 22@Barcelona innovation district (Bakıcl et al., 2013), an increasing body of literature emphasizes the growing challenge of smart city policies that risk being more focused on technology-push than on demandpull, where citizens are treated as users and consumers rather than producers and sources of creative innovation (Hollands, 2008; Söderström et al., 2014; Yigitcanlar et al., 2019). The numerous assumptions behind smart city labs and innovation districts are open to questions: What happens when there is the unavailability of research-intensive higher education institutions? Will these cities survive if there is a lack of skilled ICT workforce to create a start-up innovation culture? How will the cities in developing economies roll out smart cities without an extensive telecommunications infrastructure base? What happens when resources are scarce for governments to provide tax relief and liberalized environments for big businesses to flourish? While smart city urban regeneration areas can create new opportunities for innovation and improve service delivery, they have also proven to promote spatial inequalities by concentrating resources and infrastructure in select enclaves (Caprotti, 2014). Such processes pose a barrier to designing sustainable and inclusive cities, especially in the Global South, where a significant share of urban populations live in acute poverty (Teferi \& Newman, 2017). This article addresses some of these contradictions in urban planning literature while providing a detailed case study analysis of India's ongoing smart cities development.

\section{Methodology}

This study accessed the smart city policy document for each of the 100 selected cities under the SCM (available through https://smartnet.niua.org). Only the winning city proposals approved for funding by the Indian government were chosen. A content analysis of these proposals was undertaken to identify the smart city vision and processes employed for the plan preparation by the cities. The proposals were also scanned for identifying the area and population coverage of the ABDs, across cities that allow us to measure the spatial inequality and intra-urban disparities. A series of smart city project-level information was collected from the cities' profiles (Ministry of Housing and Urban Affairs, 2021a) to identify the project names and itemized costs outlined by cities in the smart city proposal. These data were later transformed to present the sector-wise analysis depicting the networks of investments. The study also referred to the smart cities' dashboard (Ministry of Housing and Urban Affairs, 2021b) from the Indian Ministry of Housing and Urban Affairs that publish city and project level implementation progress reports. This source was used to compile data on the city-wise number of project tender issued, projects completed, and fund utilization efficiency as of April 20, 2021.

The quantitative data was processed through $R$, an open-sourced programming language for statistical computing. Functions from "tidyr" packages of "tidyverse" in the R library were first used to transform the data, so it is more evenly distributed across the graph. Data transformation was also necessary to calculate a simple correlation coefficient between variables (area coverage and population coverage of $A B D$ ) that need to show a linear relationship. Through the data transformation process, functions in $\mathrm{R}$ were explored to sort out the observations, select variables or columns, and filter observations by their values, and summarize data into groups. The study used a combination of "ggplot2" in R and Datawrapper (available at https://www.datawrapper.de) to build the visualizations and charts offering both static visuals for 
print articles and open codes to embed live and interactive visualization with online articles.

\section{Deconstructing the Area-Based Smart City Development Approach Advocated by the Smart Cities Mission in India}

\subsection{Smart Cities as a Response to India's Grand Urbanization Challenges}

The urban landscape in the world's largest democracy and fastest-growing major economy-India-is changing dramatically, with the urban population increasing from $18 \%$ in 1961 to 32\% by 2011 (Office of the Registrar General \& Census Commissioner, 2021). By 2030, 590 million people will live in India's cities, with a net increase of 270 million in working-age population (Sankhe et al., 2010). There will be more than 68 million cities in the country by 2030, whereas all of Europe currently has 35 such urban agglomerations. Urban policymakers in India have somewhat failed to match the growing complexities of urban problems with adequate planning, governing instruments, and physical infrastructure. United Nations placed India at position 131 among 182 countries according to a citizen's quality of life ranking (United Nations Development Programme, 2020). Recently, the World Health Organization announced that half of the world's 20 most polluted cities are in India. McKinsey \& Company rated the performance of Indian cities in the areas of urban planning, finance, and governance as inferior-the lowest rating on a four-point scale (Sankhe et al., 2010). Such poor standing across global benchmarks has somewhat forced India's Ministry of Housing and Urban Affairs to lay out a new strategy in which local governments must think innovatively and transform service delivery models to avoid urban decay and ensure the competitiveness of cities leading to the launch of SCM in 2015.

\subsection{Defining the Goals and Approach of the Smart Cities Mission}

According to the guideline issued by the Ministry of Housing and Urban Affairs, the purpose of the SCM is to drive economic growth and improve the quality of life of people by enabling local area development and harnessing technology that leads to smart outcomes (Ministry of Housing and Urban Affairs, 2021c). The guideline also highlights that the mission is an urban renewal and retrofitting program to develop smart cities across the country, making them citizen-friendly and sustainable. Although the initiative primarily focuses on technology and urban renewal, the authorities did not provide a clear definition of the "smart city" concept. The SCM guideline states that there is no universally accepted definition of smart city as the meaning is interpreted differently by people, cities, and countries depending on their development trajectories and future aspirations. Many believe such an approach from the current regime inad- vertently encouraged a more active role by the multinational corporations in shaping the smart city rhetoric (Praharaj \& Han, 2019b). Not surprisingly, big tech companies such as PwC, Deloitte, and Cisco launched their signature smart city reports in India. Furthermore, the Ministry of Housing and Urban Affairs engaged them as project management consultants for handholding cities for smart city plan preparation and implementation.

Immediately after the launch of SCM, Cisco introduced a report to assert that digital urbanism is no more a fiction in India (Cisco, 2015). It claimed that a smart city refers to a meticulously planned city relying on ICT as an enabler to solve many urban problems (Cisco, 2015, p. 5). In the same year, PwC produced a publication that depicts the smart city concept where an ICT master plan builds on the foundation and increased digitization, offering a more sustainable and livable environment for the citizens (PwC, 2015). The report mentioned that smart cities in India must promote "modern urbanization with an organic integration of IT with the physical, social and business infrastructure in cities" (PwC, 2015, pp. 8-9). Another global conglomerate, Deloitte (2015, p. 4), in its report 100 Smart Cities in India: Facilitating Implementation, argued that "smart cities exist on the intersection of digital technology, disruptive innovation and urban environments." The report further recommended that Indian cities leverage a "cloud-based ICT solution capable of integrating data from various sources and generating fast responses" for better infrastructure management and delivery (Deloitte, 2015, p. 4).

While the SCM guidelines did not clarify the smart city definitions, it proposed a development model for cities to design and implement projects that focuses on $A B D$ and also the solutions that will have a city-wide impact. The Ministry of Housing and Urban Affairs asserted that $A B D$ vis-à-vis new technologies acts as agents of transformation of existing areas through retrofitting or redevelopment strategies to improve the livability of urban precincts. These select areas will then act as lighthouses for other parts of the city as a best practice model to be replicated within and across regions. In contrast, pancity development envisages improvements in the delivery and management of existing infrastructure or construction of new facilities to have a city-wide impact. The national government proposed that cities must leverage technology, information, and data to create smart solutions to urban problems in developing the pan-city infrastructure projects. The SCM website elaborates on a host of smart solutions, including intelligent traffic management systems, smart water metering, video crime monitoring, smart parking, telemedicine, smart energy, and sensor-based waste management.

\subsection{Untangling the Smart Cities Area-Based Development Model}

An analysis of the smart city plans undertaken through this study reveals that the 100 cities allocated a 
staggering $81 \%$ of total funds for $A B D$. The national smart cities guideline encouraged cities to focus both on $A B D$ and pan-city infrastructure, but soon after the individual city proposals came to light, it was becoming apparent that they decisively moved towards creating area-based urban regeneration creating space for technology experiments to develop smart precincts within cities. Overall, the national program funds one areabased project in each city that would showcase 100 smart precincts across the 100 cities.

The SCM outlines three strategic components of area-based smart city development (see Figure 1): city improvement (retrofitting), city renewal (redevelopment), and city extension (greenfield development). They propose retrofitting techniques for existing built-up areas to achieve the smart city objectives by enhancing the efficiency and livability of neighborhoods. The size of the selected area must be 500 acres or more for retrofitting model implementation. Rather than suggesting an enhanced land consolidation strategy, the guidelines expect existing structures to remain intact and call for some handpicked smart solutions injected into the identified area via the retrofitting approach. Examples of retrofitting projects include installing Wi-Fi hotspots, energy-efficient LED street lighting, CCTV surveillance, smart water metering, and intelligent traffic and parking management solutions.

Redevelopment models will affect a more significant makeover of the existing built-up environment with the development of new layouts, enhanced infrastructure, and using mixed land use and increased density strategies. As per the SCM guidelines, a redevelopment project shall cover over 50 acres and emphasize a higher floor space index, high ground coverage over the selected land parcel, and the release of more green spaces. The vision of this development model is influenced by the former town planning schemes of Gujarat and Maharashtra, considered the best available land development models in India. Smart city redevelopment precincts engage in projects such as road widening: pedestrian and bike infrastructure development, design-implementation of waterfront public spaces, and high-intensity mixed-land use development around public transit stations.

Greenfield development seeks to introduce advanced infrastructure solutions in a greenfield area (over 250 acres) using modern planning strategies, green technologies, and innovative financing and implementation tools. The Ministry of Housing and Urban Affairs (2021c) explicitly suggest that greenfield developments should address the needs of the expanding population

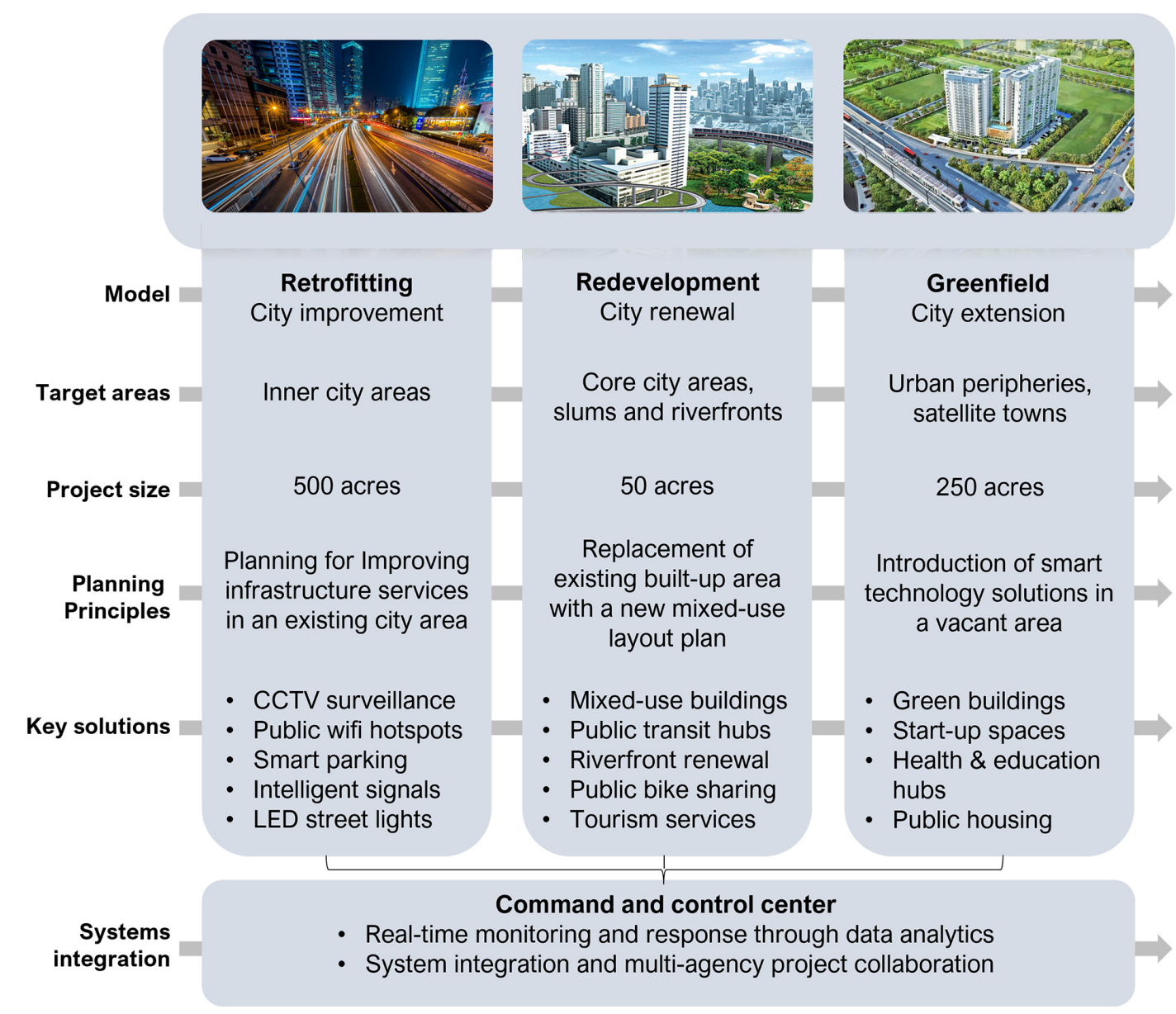

Figure 1. ABD model of the smart cities in India. 
in urban peripheries to tackle future growth while also providing high-end infrastructure for attracting businesses. While the retrofitting and redevelopment strategies implemented within the limits of the core city area, greenfield development ideally take place beyond them but within the jurisdiction of the metropolitan authority. Key features and projects of greenfield city extension are green buildings, adequate provision for affordable housing, quality health and recreation facilities, trade facilitation, and startup incubation centers.

The smart cities in India have set out an ambitious plan to develop integrated command and control centers for building synergy between various projects and monitor the performance of urban services and infrastructure (Praharaj, 2020). These centralized urban monitoring systems connect, integrate, and analyze information streamed by the sensors and digitally instrumented devices plotted across the city, somewhat embracing the model of data-driven networked urbanism (Townsend, 2013). The command center projects are based on the premise that rich seams of data can capture, model, and predict the urban processes (Batty et al., 2012) and guide the design of future urban policies and interventions. Moreover, they act as a systems integrator to increase interoperability between various projects and solutions developed by different vendors within the $A B D$ and citywide projects, as well as offering a platform for multiagency collaboration for planning and designing rapid response to emergencies.

\section{Critical Analysis of the Area-Based Smart City Development Processes and Outcomes in India}

\subsection{What Processes Were Employed for the Selection of Areas for the Smart City Pilot Project?}

As outlined earlier in the study, each designated smart city in India selected a particular area for precinct-scale pilot project development. Hence, the contentious issue in the entire development process was: Which area of the city is chosen and how do governments make the selection? An analysis of 100 smart city proposals in this research suggests that authorities primarily relied on voting through online portals and social media to prioritize and identify locations for an area-based urban renewal project implementation. A review of the smart city proposal of Bhunaeswar - the first-ranked smart city by the Ministry of Housing and Urban Affairs-reveals that $26 \%$ of the urban population voted in the consultation process, with a substantial number of votes recorded on the government website and through social media drives. Pune city, which received the highest funding allocations through the SCM, boasts on its website (Pune Smart City Development Corporation, 2020) that it has undertaken the largest envisioning exercise in the history of Indian cities, a full-fledged $24 \times 7$ virtual war room enabling them to attract participation from 3.5 million citizens. However, the claim appeared to be grossly exaggerated, as the Census of India data shows only 3.12 million people living in the city (Office of the Registrar General \& Census Commissioner, 2021). A relatively smaller town in the Himalayan region of India, Agartala, could only engage $11.3 \%$ of the city population for its smart city proposal.

The analysis in this study indicates an average of 10 to $15 \%$ of the citizens in each city took part in the public participation processes. It is not just that a high majority of people were left out of the consultation process, but an over-reliance on digital means of engagement undermines the value and contribution of the non-digitally inclined population. The citizen engagement mechanisms deployed in the aspiring smart cities failed to acknowledge the challenges posed by the "digital divide," that is, the deep-rooted social and economic inequalities that come about as a result of who has access to communication technology and how they use it. A quick fact-finding from the Census 2011 data shows that a meagre average of $9.8 \%$ of households in Indian cities has an internet connection at home (Office of the Registrar General \& Census Commissioner, 2021). Household internet access in smaller towns under the SCM such as Pasighat, Dahod, Kavaratti, Satna, Rampur, Sagar, Agartala, and Dindigul is even below $5 \%$. Only seven out of 100 smart cities provide over $20 \%$ of households with internet infrastructure. We found the reflection of this digital divide in the areas prioritized for ABD. In the Indian capital of New Delhi, Cannaught Place was selected under the ABD project as it attracted a high number of citizens votes. This exclusive zone has a significant concentration of skilled workforce and serviced industries which meant that people living or working in these clusters could voice their preferences over the rest of the city.

A recent report by the Housing and Land Rights Network (2018) verifies that participation of low-income communities in the smart cities' consultation process has been inadequate. The global agency surveyed five different locations in Bhubaneswar-where nearly half the population affected by $A B D$ lives in slums - to find that none in the disadvantaged settlements were consulted, nor were the residents aware of what smart city development meant for the city or for them (Housing and Land Rights Network, 2018). These findings point to cutting loopholes in the project visioning and prioritization process adopted by emerging smart cities, challenging their sustainability. There is an increasing risk of spatial inequality in physical infrastructure development and the potential of the digital divide between communities as a consequence of such flawed designs.

\subsection{Do the Area-Based Development Projects Promote Spatial Inequality and Intra-Urban Disparity?}

This study investigates the scale and reaches of the ABD projects across the 100 cities to measure the mission's inclusiveness. An analysis of the smart city proposals in 
Figure 2 shows that ABD projects impact less than $5 \%$ of the total area per city. This research analyzed data from 75 submissions for which information is available. While there is some variation in the area covered by these cities, an overwhelming number of them (58 out of 75 ) allocated less than $10 \%$ of the urban authority area for smart precinct development. This analysis found that 41 out of the 75 cities earmarked less than $5 \%$ of the urban expanse for ABD. In Ludhiana, only $0.3 \%$ of the city's total area is covered under the SCM, while in Ahmedabad and Jaipur it is $0.5 \%$. The site developed as a smart city in New Delhi accounts for $0.6 \%$ of the total city area, which is only $0.0015 \%$ of the total area of the National Capital Territory of Delhi. The cities of Pune,
Indore, Lucknow, Amravati, Guwahati, Ranchi, Nashik, and Kota have defined just $1 \%$ of the municipal area under the smart city ABD.

Research into the population served by the $A B D$ projects undertaken in this study reveals that only up to one-tenth of the urban population per city is targeted under the proposals. In Pune, a meagre 0.8\% of the population will be impacted; in Nashik, 1\%; in Ahmedabad, 1.5\%; in Bhopal, 1.7\%; in Lucknow, 2.5\%; in Nagpur, 2.6\%; and in Chennai, 3.4\%. The scatterplot in Figure 3 characterizes this trend, wherein quadrant $B$, a number of smaller towns showcase a higher share of population and city area served by ABD. Whereas, in Quadrant A, as many as 29 cities, mostly large ones,
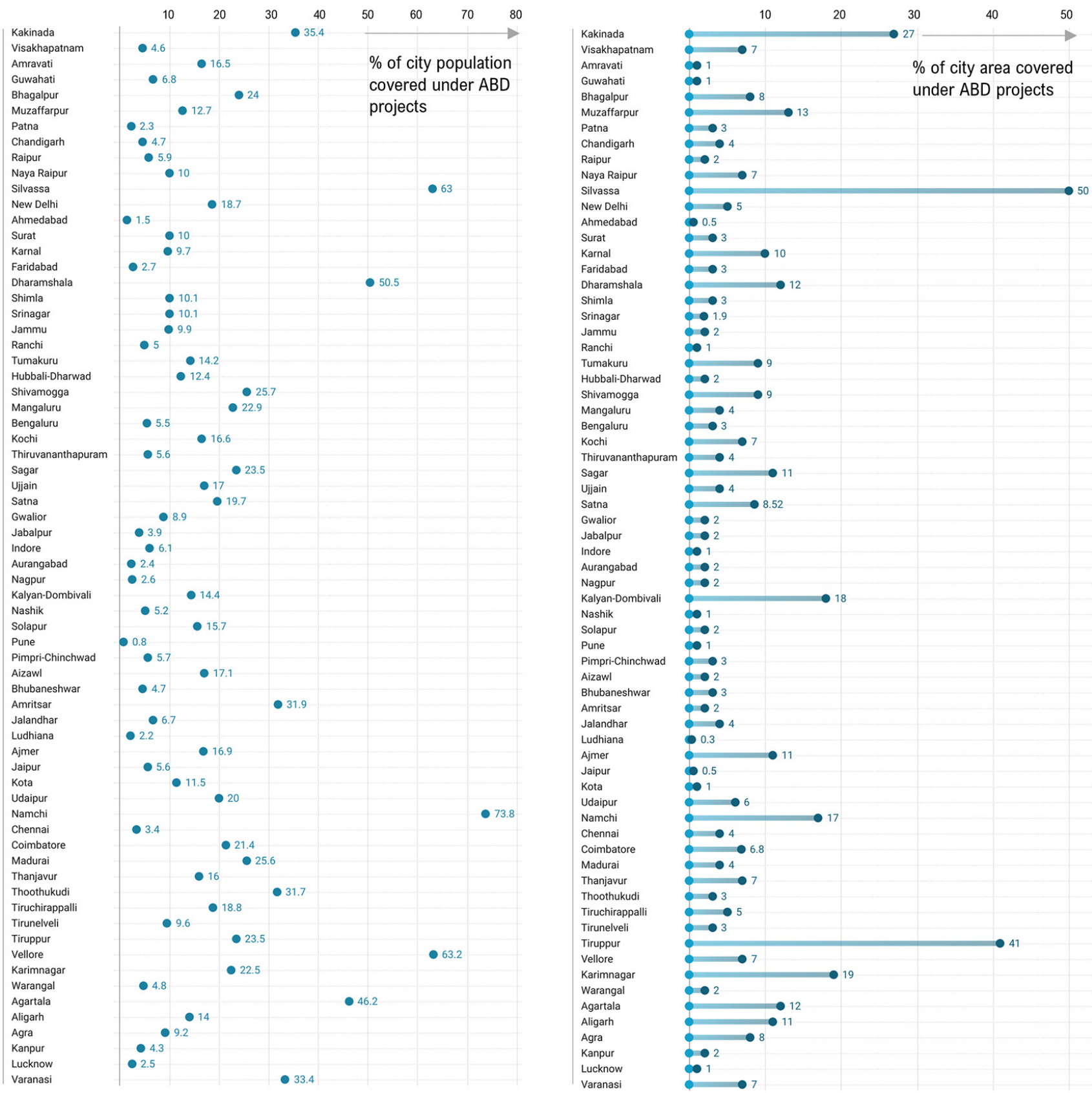

Figure 2. Quantification of the city area and population covered under the ABD projects. 


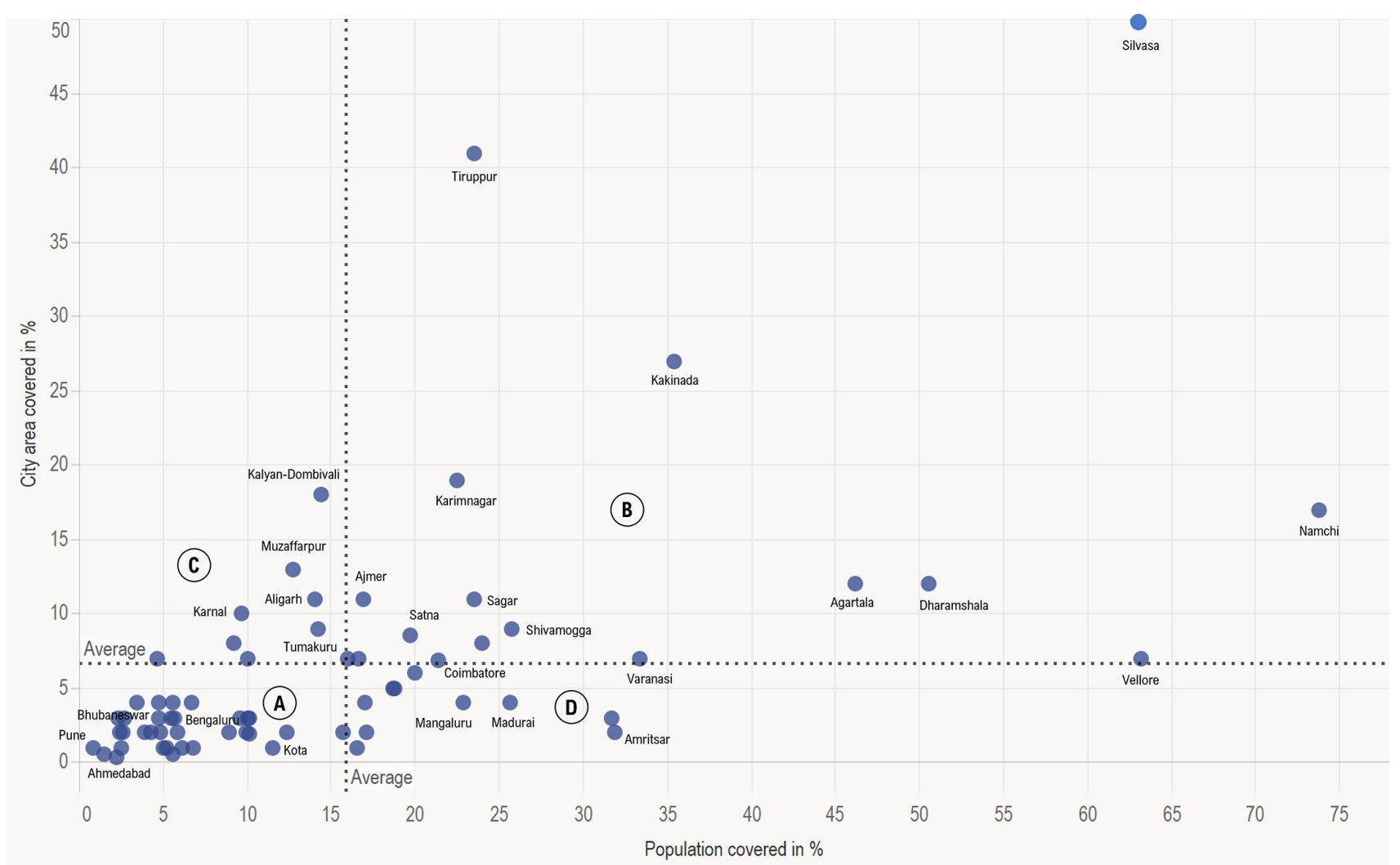

Figure 3. Typologies of cities based on area and population coverage under the ABD projects. Notes: Quadrant A: Low city area and population coverage; Quadrant B: High city area and population coverage; Quadrant C: High city area and low population coverage; Quadrant D: High population and low city area coverage.

show below-par area and population coverage under the ambit of the smart city urban renewal program. Cities that have adopted a more inclusionary approach to include a more substantial share of population under the ABD are Port Blair (77\%), Namchi (74\%), Pasighat (63\%), and Vellore (63\%).

Thus, the analysis reveals that $81 \%$ of the investments under the SCM allocated for ABD will impact one out of ten people in the 100 selected cities. In the large cities, an average of three out of 100 people will be benefited from ABD projects. The skewed investment towards the development of elite enclaves reinforces existing power geometries and social and spatial inequalities rather than eroding or reconfiguring them. These pilot urban renewal ventures fuel the debate on the possible class inequality effects of policies oriented towards creating smart cities by prioritizing certain areas over others, deepening intra-city inequalities against principles of democratic and sustainable urban development processes. The findings resonate with what Kitchin (2014) emphasized: Smart cities are the vision of certain vested interests, and they serve the interests of those constituencies, both through enacting their sensibilities and politics, and by advancing their economic concerns and material desires. Such approaches have long-term consequences on how infrastructure is planned and distributed, how resources are allocated, and on who can access them within and across cities and regions.

\subsection{Local Issues or Global Technology Solutions? A Sector-Wise Analysis of Smart City Urban Renewal Investments}

This study brings together data from the various projects and investments identified in the smart city proposals to categorize them under broad sectors. The analysis presented in Figure 4 shows investment share in various sectors across 100 smart cities and the number of projects undertaken by the 33 cities selected in the first and second phase of the SCM. The urban mobility sector received the highest priority, with more than one-fourth of the investment allocated through the program. Economic development, including establishing start-up clusters and innovation spaces within $A B D$, was issued over $15 \%$ of the funds under the SCM. ICT and centralized command and control center projects attracted nearly $14 \%$ of the total spending. Education and health sectors and solutions that improve environmental quality and management received the most negligible share of investment (just over $3 \%$ each). The analysis suggests that Indian smart cities design favors "hard infrastructure" domains such as transport and utilities where largescale technology deployment is likely, with a significant presence of vendors in the market having numerous "plug and play" digital solutions. In contrast, "soft infrastructure" domains like education, health, and affordable housing, where ICT application has a seemingly limited 


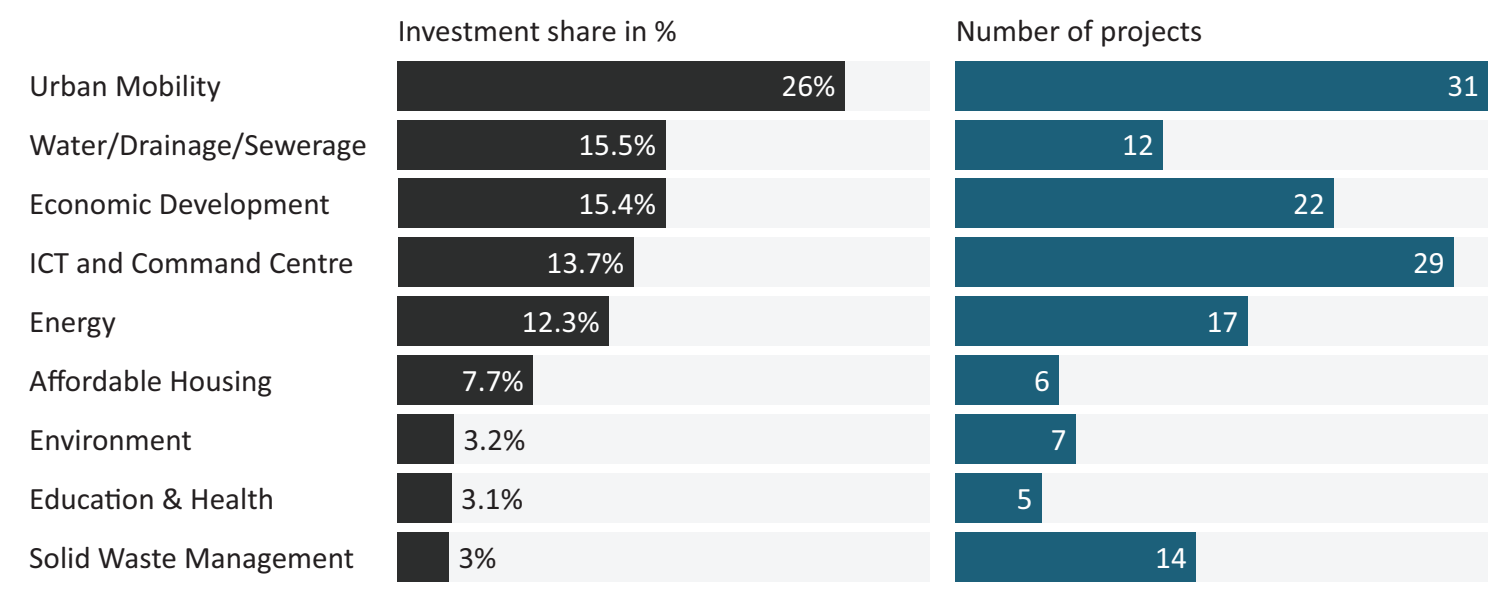

Figure 4. Sector wise investments and projects identified in the smart city proposals. Notes: Investment share was calculated from smart city proposals from across 100 cities. The number of projects reflects data from the 33 cities selected in the first and second phase of the SCM in India.

role (Caragliu et al., 2011), was ignored with limited activities proposed in the sector.

While the Indian smart city plans suffer from a narrow spatial focus and developments targeted exclusively of handful sectors and ICT solutions, recent studies emphasize the need for critical social infrastructure for sustainable development in the region. Praharaj and Han (2019a), while building a typology of these 100 smart cities using a series of key performance indicators, found that social capital, including education, health facilities, and lack of access to housing, severely impact the quality of life in small and medium-sized towns in India. Similarly, Rana et al. (2019) asserted that environmental challenges of growing pollution, social challenges of urban safety, and lack of community services are significant barriers to smart city development in the Indian context. Overall, these analyses show that the SCM lacks an objective approach to engage with local issues. Instead, the attempted design of high-tech urban precincts and elegant digital solutions through vendor-driven policy and technology mobilities suggests that aspiring smart cities concentrate on building "smart utopias" rather than "smart realities." As Datta (2015) explains, attempts to provincialize western models of smart urbanism in India show no concern for producing socio-political and material outcomes. Instead, such utopian urban planning envisages urbanization as a business model rather than a model of social justice for sustainable cities.

\subsection{The Likelihood of Increased Segregation and Gentrification From Smart City Area-Based Development}

This research finds that 92 among the 100 cities have adopted redevelopment and retrofitting models for $A B D$ that target urban core and central business districts. Ironically, a large number of populations in the inner-city areas across India lives in slums. As per the 2011 Census (Office of the Registrar General \& Census Commissioner, 2021), nearly 14 million households live in urban slums, with three million homeless living on city streets in India. The drive for smart cities is triggering evictions of people from slums and informal settlements. There are already reports of slum demolition from Indore, Bhubaneswar, Delhi, and Kochi without adequate compensation or alternate accommodation (Housing and Land Rights Network, 2018). Besides state-sponsored evictions, there is a growing likelihood of market-driven evictions in some of these smart city enclaves due to a sharp increase in rental rates and housing prices. Experience from global cities suggests that high-quality services and concentrated prosperity of workers in the digital economy lead to rising rents and increased demand for housing that places disadvantaged citizens, such as slum dwellers and urban poor, at risk. For example, Caprotti (2014), examining the smart Chinese cities, found that materialization of flows of capital and smart technologies in urban centers leads to glittering real estate developments built from scratch by lowpaid workers, in which they cannot afford to live themselves, and these geographies of inequality often see lowincome households denied access to schooling and critical healthcare. This constitutes the generation of a class of "new urban poor" on the fringes of flagship smart cities and other spectacular urban developments.

The area-based smart city development in India promises high-quality infrastructure and ICT-driven services, including free $\mathrm{Wi}-\mathrm{Fi}$, improved traffic control, intelligent sensors, and better utilities with significant contribution from the private sector participation and investment. The SCM guidelines encourage cities to charge higher taxes and user fees for providing modern infrastructure, a convenient policy to attract private capital. The Housing and Land Rights Network (2018, p. 41) quotes the Pune city CEO, saying: "The government is spending more than Rs 1,000 crore for better infrastructure and facilities in the $A B D$ area. Since the area residents are getting better infrastructure, they won't mind paying increased water charges and taxes." 
The high quantum of charges for essential services like water and sanitation could potentially increase the financial burden on the poor, pushing the low-income groups to city peripheries. Thus, smart city policies and technologies in India threaten to marginalize particularly those in acute poverty and informal economies, leading to irreversible consequences of economic, spatial, and cultural polarization.

\subsection{Does the Area-Based Smart City Strategy Enable Convergence and Integration?}

This section positions the smart city ABDs within the broader context of urban planning and policymaking in India to examine how the SCM aligns with the overarching city goals. Alongside the SCM, the Ministry of Housing and Urban Affairs announced the Atal Mission for Rejuvenation and Urban Transformation, focusing on infrastructure upgradation across 500 cities in India and the Housing for All mission to supply affordable housing for the poor in 305 cities. The Ministry of Culture simultaneously implements the National Heritage City Development and Augmentation Yojana to preserve and revitalize cities with heritage character. These mega schemes are accompanied by the Clean Indian Mission for improving urban sanitation and the Digital India program to ramp up fiber infrastructure connectivity across the large cities. Most of the 100 smart cities are entrusted with implementing these schemes simultaneously, raising apprehension about the occurrence of multiple planning documents with different visions emerging from these programs. A close look at the SCM guideline shows it did not have a framework or outline regarding how these different initiatives will be coordinated for the cities' common good.

As cities are beginning to engage in smart city projects, it is becoming apparent that they are looking to implement pilot projects focusing on a narrow scope with high visibility. There is an absence of strategies to integrate smart city projects with existing planning instruments. For example, this study finds that there are at least eight different plans simultaneously being executed in the city of Bhubaneswar, all aiming at urban development, either holistically or focused on a sector. The smart city proposal is unconnected and has little convergence with the existing state and city-level statutory plans. In stark contrast to the Comprehensive Development Plan, which emphasizes strengthening existing traditional industries and heritage zones, the Smart City Plan promotes technology and knowledge-based enterprises.

A lack of cohesive approach to development and continuous experimentation with new plans work as barriers to project implementation and achieving sustainable urban development goals. Figure 5 shows the fund utilization efficiency and project completion performance of the top 20 cities selected in the first phase

\begin{tabular}{|c|c|c|c|}
\hline Cities & $\begin{array}{r}\text { Number of project } \\
\text { tender issued }\end{array}$ & $\begin{array}{r}\text { Number of projects } \\
\text { completed }\end{array}$ & $\begin{array}{l}\text { Fund utilization } \\
\text { efficiency (\%) }\end{array}$ \\
\hline Chennai & 45 & 37 & $62 \%$ \\
\hline Kakinada & 93 & 51 & $47 \%$ \\
\hline Indore & 280 & 226 & $46 \%$ \\
\hline Surat & 87 & 64 & $43 \%$ \\
\hline Udaipur & 128 & 68 & $36 \%$ \\
\hline Belagavi & 217 & 126 & $33 \%$ \\
\hline Bhopal & 96 & 55 & $28 \%$ \\
\hline Ahmedabad & 73 & 42 & $24 \%$ \\
\hline Coimbatore & 72 & 55 & $22 \%$ \\
\hline Pune & 60 & 19 & $18 \%$ \\
\hline Jaipur & 143 & 35 & $17 \%$ \\
\hline Visakapatnam & 66 & 41 & $17 \%$ \\
\hline Jabalpur & 97 & 42 & $15 \%$ \\
\hline Davanagere & 106 & 36 & $11 \%$ \\
\hline Solapur & 46 & 23 & $6 \%$ \\
\hline Ludhiana & 46 & 8 & $6 \%$ \\
\hline Guwahati & 10 & 3 & $1 \%$ \\
\hline
\end{tabular}

Figure 5. Status of project completion and fund utilization by the top 20 cities selected in the first phase of SCM. Note: Data for three cities in this list (Bhubaneswar, Kochi, and New Delhi) were not available. 
of the SCM. These cities were supposed to complete all project delivery by January 2021 as per the SCM deadline. However, the data collected through this research on April 20, from the Ministry of Housing and Urban Affairs' (2021b) website, highlight that nearly half of those cities are struggling even to spend one-fifth of the funding allocated. Guwahati could spend as much as $1 \%$, and Solapur and Ludhiana consumed 6\%. Dvangere completed just one-third of the projects identified in the smart city proposal, whereas Jaipur implemented 35 out of 143 projects. The below-par performance in project execution by the so-called top-ranked smart cities exposes the acute lack of capacity, planning, and desired impact of the grand utopian scheme.

\section{Discussion and Conclusions}

The much-debated concept of smart cities can potentially play a significant role in addressing sustainability and quality of life issues in cities. At the same time, there are severe challenges posed by the emergence of technology and business-driven urban development processes. This article critically analyzed India's SCM to highlight the design, implementation, and impact of a new area-based urban development model implemented across 100 cities with global implications. The three strategic components of area-based smart cities-retrofitting, redevelopment, and greenfield development-somewhat reflect the aspirations of living labs (such as the 22@Barcelona) and innovation districts (e.g., Medellínnovation District of Medellín, Colombia) where ICT infrastructure, clustering of innovative businesses, and neoliberal urban spaces serve a digitally-inclined "creative class" (Florida, 2005). This study finds that although the smart cities program is a timely initiative considering the surging urbanization and multifaceted challenges facing Indian cities, there are flaws and inconsistencies in the narrative, design, and implementation.

Results show that area-based urban renewal projects in Indian smart cities follow an exclusionary development approach, targeting an average of less than 5\% of the city area and denying nine out of 10 people the new services and opportunities. The SCM allocates over $80 \%$ of the investment for just $10 \%$ of the urban populations across the 100 selected cities set to exacerbate intra-urban contrasts. The selection of elite localities through online and social media voting throws light on the new-age smart city that promotes the "digital divide" rather than enforcing "digital inclusion." Instead of developing social infrastructure (education and health) and affordable housing to meet the challenges of urban poverty, slums, and basic services, the SCM predominantly invests in building smart city command and control center and ICT-oriented services. In the promise of better high-quality infrastructure, the ABD model leads to evictions of slum dwellers and forced migration of lowincome communities out of the business districts due to a sharp increase in rents, taxes, and amenity fees. These findings suggest that cities with a broader portfolio of investments in "smart" initiatives are not necessarily better or more livable. Instead of attaining a fairer democracy and quality of life, it may turn into a dystopian, anti-people environment where urban spaces are used to create business opportunities for corporate profits. However, the study finds that small and mediumsized towns, such as Pasighat, Silvassa, Vellore, Port Blair, Namchi, Kakinada, Agartala, Varanasi, Thoothkudi, and Amritsar, show cognizance of the social and cultural implications of the smart city movement in India to include a significant share population within their smart city ABDs. The smart city planning processes in these towns provide opportunities for in-depth research that could offer new lessons for designing sustainable future smart cities.

This study recognizes the need for Indian cities to design holistic urban planning approaches that engage and impact the diverse demographics and contested landscapes unique to the region. Mere "technological fixes" in smart enclaves will not meet the complex urbanization challenges facing cities of the global south; instead, they will lead to increased spatial inequality and socially polarizing outcomes. The smart city pilot projects should engage with the underlying environmental, economic, and social sustainability issues from the sprawling urban fringes to the congested slums and deteriorated older city areas. Social sustainability implies that smart cities have to be not just technological, but also inclusive and emphasize the construction of social relations and networks of trust and reciprocity, as well as investing in human capital to foster the urban capacity for learning and cooperative innovation (Nam \& Pardo, 2011; Yigitcanlar et al., 2019). Such a change in the urban planning approach can genuinely impact ordinary people beyond the affluent class. Smart city plans should not be conceived as standalone documents but designed around the city's core long-term visions and master plans. The findings support existing literature that suggests sustainable cities require strategies and methods that incorporate the perspectives and needs of a broad range of stakeholders (Hollands, 2008; Praharaj et al., 2018b). Simply adopting sophisticated ICT infrastructure or showcasing self-promotional business hubs will not lead to practical cities. Real smart cities require a more holistic approach to digital urban renewal that involves the devolution of power and strategies that address urban inclusion, sustainability, and resilience. These lessons are critical to support humane smart cities development in the Global South, which faces unprecedented challenges to meet the global sustainable development goals.

\section{Acknowledgments}

The author expresses sincere appreciation to Alexandria Drake, global health $\mathrm{PhD}$ candidate at Arizona State University, for proofreading the final manuscript. 
The author acknowledges the valuable and constructive suggestions provided by the reviewers during the peer-review process. The work is conducted at the Knowledge Exchange for Resilience at Arizona State University, which receives funding from the Virginia G. Piper Charitable Trust.

\section{Conflict of Interests}

The author declares no conflict of interests.

\section{References}

Baccarne, B., Schuurman, D., Mechant, P., \& De Marez, L. (2014). The role of urban living labs in a smart city. In XXV ISPIM Innovation Conference, Proceedings. ISPIM. http://hdl.handle.net/1854/LU-5646684

Bacchi, U. (2020). "I know your favourite drink:" Chinese smart city to put Al in charge. World Economic Forum. https://www.weforum.org/agenda/ 2020/12/china-ai-technology-city

Bakıcı, T., Almirall, E., \& Wareham, J. (2013). A smart city initiative: The case of Barcelona. Journal of the Knowledge Economy, 4(2), 135-148. https://doi.org/ 10.1007/s13132-012-0084-9

Batty, M., Axhausen, K. W., Giannotti, F., Pozdnoukhov, A., Bazzani, A., Wachowicz, M., Ouzounis, G., \& Portugali, Y. (2012). Smart cities of the future. European Physical Journal: Special Topics, 214(1), 481-518. https://doi.org/10.1140/epjst/e2012-01703-3

Beretta, I. (2018). The social effects of eco-innovations in Italian smart cities. Cities, 72, 115-121.

Caprotti, F. (2014). Critical research on eco-cities? A walk through the Sino-Singapore Tianjin eco-city, China. Cities, 36, 10-17. https://doi.org/10.1016/ j.cities.2013.08.005

Caragliu, A., del Bo, C., \& Nijkamp, P. (2011). Smart cities in Europe. Journal of Urban Technology, 18(2), 65-82.

Cisco. (2015). Digitizing India: Smart cities. https:// www.cisco.com/c/dam/m/en_in/innovation/ smartcities/assets/smart-cities-ebook_v7.pdf

Coe, A., Paquet, G., \& Roy, J. (2001). E-governance and smart communities. Social Science Computer Review, 19(1), 80-93. https://doi.org/10.1177/089443930 101900107

Cosgrave, E., Arbuthnot, K., \& Tryfonas, T. (2013). Living labs, innovation districts and information marketplaces: A systems approach for smart cities. Procedia Computer Science, 16, 668-677. https://doi.org/ 10.1016/j.procs.2013.01.070

Datta, A. (2015). A 100 smart cities, a 100 utopias. Dialogues in Human Geography, 5(1), 49-53. https://doi. org/10.1177/2043820614565750

Deloitte. (2015). 100 smart cities in India: Facilitating implementation. https://www2.deloitte.com/ content/dam/Deloitte/in/Documents/IMO/in-imosmart-cities-in-india-noexp.pdf
Dowling, R., McGuirk, P., \& Gillon, C. (2019). Strategic or piecemeal? Smart city initiatives in Sydney and Melbourne. Urban Policy and Research, 37(4), 429-441. https://doi.org/10.1080/08111146.2019.1674647

Downs, A. (2005). Smart growth: Why we discuss it more than we do it. Journal of the American Planning Association, 71(4), 367-378. https://doi.org/ 10.1080/01944360508976707

Florida, R. L. (2005). Cities and the creative class. Psychology Press.

Han, H., \& Hawken, S. (2018). Introduction: Innovation and identity in next-generation smart cities. City, Culture and Society, 12, 1-4. https://doi.org/10.1016/ j.ccs.2017.12.003

Hollands, R. G. (2008). Will the real smart city please stand up? City, 12(3), 303-320. https://doi.org/ $10.1080 / 13604810802479126$

Housing and Land Rights Network. (2018). India's Smart Cities Mission: Smart for whom? Cities for whom? (Update 2018). https://www.hlrn.org.in/documents/ Smart_Cities_Report_2018.pdf

IBM. (2008). A smarter planet: The next leadership agenda. https://www.ibm.com/ibm/cioleadership exchange/us/en/pdfs/SJP_Smarter_Planet.pdf

James, P. (2014). Urban sustainability in theory and practice: Circles of knowledge. Routledge.

Kitchin, R. (2014). The real-time city? Big data and smart urbanism. GeoJournal, 79(1), 1-14. https://doi.org/ 10.1007/s10708-013-9516-8

Kunzmann, K. R. (2020). Smart cities after Covid-19: Ten narratives. DisP-The Planning Review, 56(2), 20-31. https://doi.org/10.1080/02513625.2020.1794120

McCann, E. (2011). Urban policy mobilities and global circuits of knowledge: Toward a research agenda. Annals of the Association of American Geographers, 101(1), 107-130. https://doi.org/10.1080/00045608. 2010.520219

Ministry of Housing and Urban Affairs. (2021a). Cities profiles. Smartcities. https://smartcities.gov.in/citiesprofiles

Ministry of Housing and Urban Affairs. (2021b). Dashbord. Smartcities. https://smartcities.gov.in/ dashboard

Ministry of Housing and Urban Affairs. (2021c). Home page. Smartcities. https://smartcities.gov.in

Mitlin, D., \& Satterthwaite, D. (2013). Urban poverty in the Global South: Scale and nature. Routledge.

Morgan, K., \& Webb, B. (2020). Googling the city: In search of the public interest on Toronto's "smart" waterfront. Urban Planning, 5(1), 84-95. https://doi. org/10.17645/up.v5i1.2520

Nam, T., \& Pardo, T. A. (2011). Conceptualizing smart city with dimensions of technology, people, and institutions. In The Proceedings of the 12th Annual International Digital Government Research Conference (pp. 282-291). University of Maryland College Park. https://doi.org/10.1145/2037556.2037602

Nugent, D., \& Suhail, A. (2021). Crisis, disorder and 
management: Smart cities and contemporary urban inequality. In I. Pardo \& G. B. Pratos (Eds.), Urban inequalities: Ethnographically informed reflections (pp. 145-169). Palgrave Macmillan. https://doi.org/ 10.1007/978-3-030-51724-3_8

Office of the Registrar General \& Census Commissioner. (2021). Home page. Census of India. https:// censusindia.gov.in

Pancholi, S., Yigitcanlar, T., \& Guaralda, M. (2019). Place making for innovation and knowledge-intensive activities: The Australian experience. Technological Forecasting and Social Change, 146, 616-625. https://doi.org/10.1016/j.techfore.2017.09.014

Praharaj, S. (2020). Development challenges for big data command and control centers for smart cities in India. In N. Biloria (Ed.), Data-driven multivalence in the built environment. S.M.A.R.T. environments. Springer. https://doi.org/10.1007/978-3-030-12180-8_4

Praharaj, S., \& Han, H. (2019a). Building a typology of the 100 smart cities in India. Smart and Sustainable Built Environment, 8(5), 400-414. https://doi.org/ 10.1108/sasbe-04-2019-0056

Praharaj, S., \& Han, H. (2019b). Cutting through the clutter of smart city definitions: A reading into the smart city perceptions in India. City, Culture and Society, 18, Article 100289. https://doi.org/10.1016/ j.ccs.2019.05.005

Praharaj, S., Han, J. H., \& Hawken, S. (2018a). Evolving a locally appropriate indicator system for benchmarking sustainable smart cities in India. In W. Leal Filho, J. Rogers, \& U. Iyer-Raniga (Eds.), Sustainable development research in the Asia-Pacific region (pp. 253-274). Springer.

Praharaj, S., Han, J. H., \& Hawken, S. (2018b). Urban innovation through policy integration: Critical perspectives from 100 smart cities mission in India. City, Culture and Society, 12, 35-43. https://doi.org/10.1016/ j.ccs.2017.06.004

Praharaj, S., Han, J. H., \& Hawken, S. (2018c). Towards the right model of smart city governance in India. International Journal of Sustainable Development and Planning, 13(2), 171-186. https://doi.org/10.2495/sdpv13-n2-171-186

Pune Smart City Development Corporation. (2020). Home. Pune Smart City. https://punesmartcity.in

PwC. (2015). PwC smart cities PoV [PowerPoint presentation]. https://india.smartcitiescouncil.com/ system/tdf/india/public_resources/PwC-SmartCities-PoV.pdf?file=1\&type=node\&id $=2456 \&$ force

Rahmat, H., Marshall, N., Steinmetz, C., Park, M., Tietz, C., Bishop, K., Thompson, S., \& Corkery, L. (2020). The role of smart city initiatives in driving partnerships: A case study of the smart social spaces project, Sydney Australia. In R. Roggema (Ed.), Designing sustainable cities. Contemporary urban design thinking (pp. 143-159). Springer.

Rana, N. P., Luthra, S., Mangla, S. K., Islam, R., Roderick, S., \& Dwivedi, Y. K. (2019). Barriers to the develop- ment of smart cities in Indian context. Information Systems Frontiers, 21(3), 503-525. https://doi.org/ 10.1007/s10796-018-9873-4

Robinson, J. (2003). Postcolonialising geography: Tactics and pitfalls. Singapore Journal of Tropical Geography, 24(3), 273-289. https://doi.org/10.1111/1467-9493. 00159

Sankhe, S., Vittal, I., Dobbs, R., Mohan, A., Gulati, A., Ablett, J., Gupta, S., Kim, A., Paul, S., Sanghvi, A., \& Sethy, G. (2010). India's urban awakening: Building inclusive cities, sustaining economic growth. McKinsey Global Institute. https://www.citiesalliance.org/ sites/default/files/MGI_india_urbanization_ fullreport.pdf

Seta, F., Sen, J., Biswas, A., \& Khare, A. (Eds.). (2015). From poverty, inequality to smart city: Proceedings of the National Conference on Sustainable Built Environment 2015. Springer.

Shapiro, A. M. (2018). Design, control, predict: Cultural politics in the actually existing smart city [Doctoral dissertation, University of Pennsylvania]. ScholarlyCommons. https://repository.upenn.edu/ edissertations/2983

Sinky, H., Khalfi, B., Hamdaoui, B., \& Rayes, A. (2018). Responsive content-centric delivery in large urban communication networks: A LinkNYC use-case. IEEE Transactions on Wireless Communications, 17(3), 1688-1699. https://doi.org/10.1109/twc.2017. 2784433

Söderström, O., Paasche, T., \& Klauser, F. (2014). Smart cities as corporate storytelling. City, 18(3), 307-320. https://doi.org/10.1080/13604813.2014.906716

Teferi, Z., \& Newman, P. (2017). Slum regeneration and sustainability: Applying the extended metabolism model and the SDGs. Sustainability, 9(12), Article 2273. https://doi.org/10.3390/su9122273

Townsend, A. M. (2013). Smart cities: Big data, civic hackers, and the quest for a new utopia. W. W. Norton \& Company.

United Nations. (2019). World population prospects 2019: Highlights. https://population.un.org/wpp/ Publications/Files/WPP2019_Highlights.pdf

United Nations Development Programme. (2020). The next frontier: Human development and the Anthropocene (Human Development Report 2020). https://report.hdr.undp.org

Wiig, A. (2015). IBM's smart city as techno-utopian policy mobility. City, 19(2/3), 258-273.

Yigitcanlar, T. (2015). Smart cities: An effective urban development and management model? Australian Planner, 52(1), 27-34. https://doi.org/10.1080/ 07293682.2015 .1019752

Yigitcanlar, T., Adu-McVie, R., \& Erol, I. (2020). How can contemporary innovation districts be classified? A systematic review of the literature. Land Use Policy, 95, Article 104595. https://doi.org/10.1016/ j.landusepol.2020.104595

Yigitcanlar, T., Kamruzzaman, Md., Foth, M., Sabatini- 
Marques, J., da Costa, E., \& Ioppolo, G. (2019). Can cities become smart without being sustainable? A systematic review of the literature. Sustain- able Cities and Society, 45, 348-365. https://doi.org/ 10.1016/j.scs.2018.11.033

\section{About the Author}

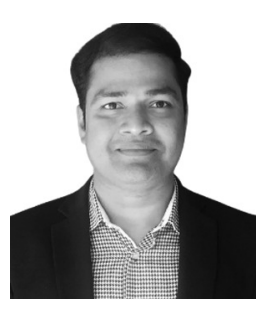

Sarbeswar Praharaj (PhD) is the associate director and assistant research professor at the Knowledge Exchange for Resilience, School of Geographical Sciences and Urban Planning at Arizona State University (ASU). He is a senior global futures scientist at the Julie Ann Wrigley Global Futures Laboratory. Before joining ASU, he was a postdoctoral researcher and manager of the City Analytics Lab at the City Futures Research Center, UNSW Sydney. Dr. Praharaj leads research on smart cities, data visualization and city dashboards, and resilience. He engages in research-led interactive teaching and learning pedagogies in urban planning and geographical science. 